\title{
RAPID
}

PUBLICATIONS

\section{Suppression of Atherogenesis in Cholesterol-fed Rabbit Treated with Nifedipine}

\author{
Philip D. Henry and Karen I. Bentley, Cardiovascular Division, Department of \\ Medicine, Washington University School of Medicine, St. Louis, Missouri 63110
}

A B S T R A C T We tested the effects of nifedipine, a calcium antagonist, on atherogenesis in rabbits fed a $2 \%$ cholesterol diet. The drug was given orally, 40 $\mathrm{mg} / \mathrm{dl}$, and control rabbits received placebo. Nifedipine was well tolerated, and evoked only transient, moderate reductions in arterial pressure. Plasma total cholesterol after 8 wk before killing the rabbits was similar in the placebo and nifedipine-treated groups, averaging $1,903 \pm 138(n=13)$ and $1,848 \pm 121 \mathrm{mg} / \mathrm{dl}$ $(n=13$; mean $\pm \mathrm{SE} ; P>0.8)$. In placebo-treated rabbits, aortic lesions stainable with Sudan IV covered $40 \pm 5 \%$ of the intimal surface, and the cholesterol concentration in aortic tissue was $47 \pm 5 \mathrm{mg} / \mathrm{g}$ protein. Corresponding values for the aortas from nifedipinetreated rabbits were significantly lower and averaged $17 \pm 3 \%(P<0.001)$ and $29 \pm 2 \mathrm{mg} / \mathrm{g}$ protein $(P<0.001)$. We conclude that nifedipine suppressed atherogenesis without reducing hypercholesterolemia.

\section{INTRODUCTION}

Current evidence suggests that calcium may play a pathogenic role in atherosclerosis (1-7). In cholesterolfed rabbits, anticalcifying and hypocalcemic agents such as diphosphonates (2-5), thiophene compounds (6), and EDTA (7) have been demonstrated to exert antiatherogenic effects without reducing the dietinduced hypercholesterolemia. In this report, we show that nifedipine suppresses atherogenesis in choles-

Address correspondence to Dr. Philip D. Henry, Department of Medicine (Cardiology), Washington University School of Medicine, St. Louis, Mo. 63110.

Received for publication 23 July 1981 and in revised form 11 August 1981. terol-fed rabbits. Nifedipine and other calcium antagonists inhibit calcium entry into smooth muscle cells, but have no anticalcifying or hypocalcemic effects (8). Results suggest that intracellular accumulation of calcium, a postulated nonspecific mechanism of cell death $(9,10)$, may be important in mediating hypercholesterolemic vascular injury.

\section{METHODS}

56 male white New Zealand rabbits from a single vendor (Boswell's Bunny Farm, Pacific, Mo.) weighing 2.3-2.6 kg were housed individually under controlled conditions and randomly assigned to four equal diet and treatment groups: (a) standard pellets and placebo, (b) standard pellets and nifedipine, (c) $2 \%$ cholesterol pellets (Nutritional Biochemicals, Cleveland, Ohio) and placebo, and (d) $2 \%$ cholesterol pellets and nifedipine. The daily amount of pellets was $100 \mathrm{~g}$ for all rabbits, and water was given ad lib. Nifedipine was force-fed, two 10 -mg capsules at 7 a.m. and 7 p.m. (40 mg/d), and untreated rabbits received identical capsules without nifedipine (placebo). In each group, five rabbits were selected randomly for the study of arterial pressure during the first and last week of the diet period. A No. 21 pediatric needle was inserted into the central ear artery and taped to the ear (11). Without restraining the rabbit, the needle was intermittently connected to a Gould P23 Db pressure transducer (Gould Inc., Instruments Div., Cleveland, Ohio), which was placed at mid-chest level and attached to a Gould amplifier/recorder system. At the beginning and at the end of the diet period, blood samples were collected from the central ear artery of all rabbits into tubes containing $\mathrm{Na}_{2}$ EDTA $(1 \mu \mathrm{g} / 100 \mu \mathrm{l})$. The samples were used for the determination of the microhematocrit, and the separated plasma was analyzed for total cholesterol, triglycerides, phosphate, total protein, and albumin with a Gemini automatic analyzer (Electro-Nucleonics, Inc., Fairfield, N. J.). Plasma calcium was measured by atomic absorption spectrophotometry (see below). The rabbits were killed after 8 wk. The thoracic aorta 
was removed, cleaned of surrounding tissue, and halved with longitudinal cuts through the anterior and posterior walls. Each longitudinal half-aorta was blotted and weighed. Onehalf was quickly frozen and stored at $-70^{\circ} \mathrm{C}$, the other laid flat, intimal side up, on clear plexiglas. The preparation was glued at its edges to the plastic with Permabond 910 (Permabond International Corp., Englewood, N. J.), and stained with Sudan IV (Sigma Chemical Co., St. Louis, Mo.) as described by Holmann et al. $(4,6,12)$. A plexiglas plate covered with translucent paper was placed on the surface of the preparation. The transparent outlines and stained areas of the vessel were delineated with black ink and areas planimetered with a computerized planimeter (model 9874 A HewlettPackard Co., Palo Alto, Calif.). The frozen half-aorta was pulverized at liquid nitrogen temperature, and homogenized in $10 \mathrm{ml}$ of chloroform-methanol $(2: 1, \mathrm{vol} / \mathrm{vol})$ in a Duall homogenizer (Kontes Co., Vineland, N. J.). Fractions of homogenate were dried and used for measurements of calcium by atomic absorption spectrophotometry on a Perkin-Elmer model 303 apparatus (Perkin-Elmer Corp., Physical Electronics Div., Eden Prairie, Minn.) as previously described (13), and for estimation of protein by the method of Lowry (14). The rest of the homogenate was extracted as described by Chan et al. (6) for measurement of total cholesterol by the ferric chloride reaction (15). Small weighed tissue samples from selected arteries were fixed in $10 \%$ buffered formalin, embedded in paraffin, and stained with hematoxylin-eosin or Verhoeff-van Gieson stain.

The difference between sequential mean values in the same group was evaluated by the $t$ test for paired comparisons. The difference between mean values for planimetered lesions was analyzed by Wilcoxon's signed rank test. Values relating lesions to tissue cholesterol were assessed by the same test. Differences between group means for variables occurring in all groups were evaluated by computerized analysis of variance using the General Linear Models procedure (16).

\section{RESULTS}

Two cholesterol-fed rabbits, one receiving placebo, the other nifedipine, died of unknown cause during the diet period. Values for body weight, hematocrit, and biochemical measurements in plasma are summarized in Table I. Plasma cholesterol and triglyceride levels in cholesterol-fed rabbits given placebo or nifedipine were similar.

Effects of nifedipine and placebo on mean arterial pressure and heart rate during the 1st wk of cholesterol feeding are shown in Fig. 1. After each dose of nifedipine, mean arterial pressure decreased maximally by $10-12 \mathrm{~mm} \mathrm{Hg}(P<0.001)$, and returned to control values within $<2 \mathrm{~h}$. Responses in the same rabbits at the end of the diet period were not significantly different from those elicited during the 1st wk $(P>0.5)$, and values in control rabbits given nifedipine or placebo did not differ from those obtained in cholesterol-fed rabbits receiving the corresponding treatment $(P>0.5$ for all values).

In cholesterol-fed rabbits, the percentage of the intimal surface covered by Sudan-positive lesions averaged $40 \pm 5 \%$ (SE) in placebo-treated rabbits $(n=13)$, and $17 \pm 3 \%$ in nifedipine-treated rabbits $(n=13 ; P$ $<0.001$ ). The cholesterol concentrations in aortas from rabbits given standard pellets were $6.1 \pm 0.3 \mathrm{mg} / \mathrm{g}$ protein for the placebo group, and $6.3 \pm 0.4 \mathrm{mg} / \mathrm{g}$ protein for the nifedipine group. In cholesterol-fed rabbits,

TABLE I

Body Weight, Hematocrit, and Plasma Constituents

\begin{tabular}{|c|c|c|c|c|}
\hline & \multicolumn{2}{|c|}{ Standard diet } & \multicolumn{2}{|c|}{$2 \%$ Cholesterol diet } \\
\hline & $\begin{array}{l}\text { Placebo } \\
(n=14)\end{array}$ & $\begin{array}{l}\text { Nifedipine } \\
(n=14)\end{array}$ & $\begin{array}{l}\text { Placebo } \\
(n=13)\end{array}$ & $\begin{array}{l}\text { Nifedipine } \\
\quad(n=13)\end{array}$ \\
\hline Body weight, $g$ & $\begin{array}{c}3,201 \pm 113 \\
(2,591 \pm 68)\end{array}$ & $\begin{array}{c}3,268 \pm 121 \\
(2,524 \pm 51)\end{array}$ & $\begin{array}{c}3,058 \pm 166 \\
(2,551 \pm 63)\end{array}$ & $\begin{array}{c}3,150 \pm 158 \\
(2,590 \pm 54)\end{array}$ \\
\hline Hematocrit, vol \% & $40 \pm 0.6$ & $41 \pm 0.5$ & $\begin{array}{c}35 \pm 1.1^{*} \\
(41 \pm 0.5)\end{array}$ & $\begin{array}{c}34 \pm 0.9^{*} \\
(42 \pm 0.6)\end{array}$ \\
\hline Total cholesterol, $m g / d l$ & $45 \pm 8$ & $41 \pm 6$ & $\begin{array}{l}1,903 \pm 138^{*} \\
\quad(48 \pm 7)\end{array}$ & $\begin{array}{c}1,848 \pm 121^{*} \\
(46 \pm 6)\end{array}$ \\
\hline Triglycerides, $m g / d l$ & $90 \pm 23$ & $93 \pm 25$ & $129 \pm 30$ & $136 \pm 25$ \\
\hline Total calcium, $m g / d l$ & $13.5 \pm 0.1$ & $13.5 \pm 0.2$ & $13.6 \pm 0.2$ & $13.7 \pm 0.2$ \\
\hline Phosphorus, $m g / d l$ & $5.9 \pm 0.3$ & $6.1 \pm 4$ & $5.7 \pm 4$ & $6.0 \pm 3$ \\
\hline Total protein, g/dl & $5.9 \pm 0.4$ & $5.7 \pm 0.4$ & $6.0 \pm 0.3$ & $5.4 \pm 0.4$ \\
\hline Albumin, $g / d l$ & $4.2 \pm 0.3$ & $3.9 \pm 0.2$ & $4.1 \pm 0.3$ & $3.8 \pm 0.2$ \\
\hline
\end{tabular}

Values (means $\pm \mathrm{SE}$ ) refer to measurements obtained at the end of the diet period. Values at the onset of the period, indicated in parentheses, are given only if they differed from the subsequent values $(P<0.05$, paired $t$ test). Simultaneous comparisons among the four groups (analysis of variance, see Methods) revealed significant differences only between cholesterol groups and standard diet groups (values with ${ }^{*} ; P<0.001$ ). 


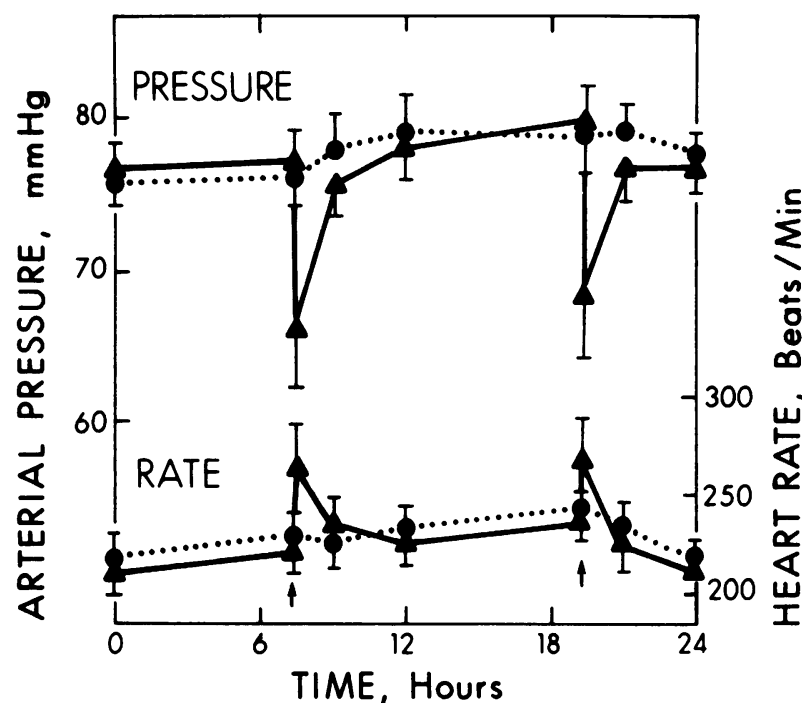

FIGURE 1 Mean arterial pressure and heart rate. Data points are means $\pm \mathrm{SE}$ from five placebo-treated $(O)$ and five nifedipine-treated rabbits $(\Delta)$ during the 1st wk of cholesterol feeding. Arrows indicate the oral administration of nifedipine $(20 \mathrm{mg})$ or placebo.

values for the placebo and nifedipine groups differed significantly $(P<0.001)$, averaging $47 \pm 5$ and $29 \pm 2$ $\mathrm{mg} / \mathrm{g}$ protein. Treatment with nifedipine altered the relationship between aortic cholesterol accumulation and formation of Sudan-positive lesions. The ratio relating planimetered lesions (percent) to tissue cholesterol (milligrams per gram protein) averaged $0.85 \pm 0.05$ and $0.58 \pm 0.04 \% /(\mathrm{mg} / \mathrm{g}$ protein) in untreated and treated rabbits $(P<0.001)$. In rabbits given standard diet, calcium concentrations in aortic tissue for the placebo and nifedipine groups were $190 \pm 11$ and $194 \pm 14 \mu \mathrm{g} / \mathrm{g}$ protein. In cholesterol-fed rabbits, aortic calcium for the nifedipine group was significantly lower than that for the placebo group, values averaging $202 \pm 14$ and $297 \pm 18 \mu \mathrm{g} / \mathrm{g}$ protein $(P$ $<0.005)$. Microscopic evaluation of aortic tissue revealed qualitatively similar lesions in the two cholesterol-fed groups, but a quantitative structural analysis was not performed in this study.

\section{DISCUSSION}

Calcium overload as a pathogenic mechanism of cell injury has been incriminated in various disorders of cardiac and skeletal muscle including catecholamineinduced cardiac necrosis $(8,13)$, myocardial ischemia $(8,13)$, myopathies $(9,17)$, and malignant hyperthermia (18). Of interest is that in the majority of these pathophysiological entities calcium antagonists effectively suppress calcium accumulation and cell necrosis $(8,13,17,18)$. Moreover, myopathic Syrian hamsters given a calcium-deficient diet exhibit fewer lesions in skeletal and cardiac muscle (17). Conversely, facilitation of calcium uptake with ionophores or membrane-active toxins such as lysophospholipids or macrolide antibiotics accelerate necrosis of isolated skeletal muscle (19) and rat hepatocytes in culture (10).

Studies showing protective effects of calcium antagonists in syndromes associated with membrane injury, calcium overload, and cell necrosis may partly explain the antiatherogenic activity of nifedipine. Atherogenesis is accompanied by an accumulation of calcium in arterial walls (1-7), and proliferation of smooth muscle cells, a key process in lesion formation, goes hand in hand with cell necrosis $(20,21)$. Necrosis of foam cells releasing membrane-active lipid, such as cholesterol, may affect the membranes of neighboring cells and accelerate cellular deterioration and turnover. Decreased necrosis associated with intracellular retention of lipid may explain why lesion formation for a given lipid accumulation was significantly decreased in nifedipine-treated rabbits. We have previously demonstrated that a high cholesterol environment sensitizes isolated arteries to the constrictor effects of calcium, consistent with increased calcium uptake after acquisition of membrane cholesterol $(22,23)$.

Although nifedipine may influence proliferating smooth muscle, the drug may act by other mechanisms. Arterial pressure is an important determinant of atherogenesis, and elevated pressure aggravates atherosclerosis in cholesterol-fed rabbits (11). Therefore, vasodilator-induced hypotension might exert protective effects, although hypotensive responses were not sustained in this study. Moreover, potent vasodilators such as nifedipine might influence arteries by increasing vasa vasorum flow (24). Calcium antagonists may act on platelets. However, nifedipine does not appear to have antiaggregating effects on human platelets $(25,26)$, and the action of verapamil and diltiazem on platelets occur only at high concentrations known to exert nonspecific effects $(8,26,27)$.

Since calcium antagonists are used extensively for the treatment of coronary artery disease (8), the present study has potential clinical implications. Unlike anticalcifying drugs (2-7), calcium antagonists are not known to affect bone mineralization, and might be evaluated in children with familial hypercholesterolemia.

\section{ACKNOWLEDGMENT}

We thank Cynthia Lucas and Malcolm Clark for excellent assistance, and Barbara Donnelly and Helen Nikolaisen for the preparation of the manuscript. We also thank Dr. Ken Schechtman, Department of Biostatistics, Washington University, for the statistical analyses, and Dr. Joseph Williamson, Department of Pathology, Washington University, for the 
computerized planimetry. We are indebted to Dr. Stanley Fishman and Dr. David Poorvin for their support and making nifedipine (Pfizer Pharmaceuticals, Pfizer Inc., New York.) available to us.

This work was supported in part by grants HL 21187; SCOR HL 17646 from the National Institutes of Health.

\section{REFERENCES}

1. Blumenthal, H. T., A. I. Lansing, and P. A. Wheeler. 1944. Calcification of the human aorta and its relations to intimal arteriosclerosis, ageing, and disease. Am. J. Pathol. 20: 665-679.

2. Rosenblum, I. Y., L. Flora, and R. Eisenstein. 1975. The effect of disodium ethane-1-hydroxy-1,1-diphosphonate (EHDP) on a rabbit model of athero-arteriosclerosis. Atherosclerosis. 22: 411-424.

3. Potokar, M., and M. Schmidt-Dunker. 1978. The inhibitory effect of new diphosphonic acids on aortic and kidney calcification in vivo. Atherosclerosis. 30: 313-320.

4. Kramsch, D. M., and C. T. Chan. 1978. The effect of agents interfering with soft tissue calcification and cell proliferation on calcific fibrous-fatty plaques in rabbits. Circ. Res. 42: 562-571.

5. Hollander, W., J. Paddock, S. Nagraj, M. Colombo, and B. Kirkpatrick. 1979. Effects of anticalcifying and antifibrotic drugs on pre-established atherosclerosis in the rabbit. Atherosclerosis. 33: 111-123.

6. Chan, C. T., H. Wells, and D. M. Kramsch. 1978. Suppression of calcific fibrous-fatty plaque formation in rabbits by agents not affecting elevated serum cholesterol levels. Circ. Res. 43: 115-125.

7. Wartman, A., T. L. Lampe, D. S. McCann, and A. J. Boyle. 1967. Plaque reversal with MgEDTA in experimental atherosclerosis: elastin and collagen metabolism. J. Atheroscler. Res. 7: 331-341.

8. Henry, P. D. 1980. Comparative pharmacology of $\mathrm{Ca}^{++}$ antagonists. Am. J. Cardiol. 46: 1047-1058.

9. Wrogemann, K. 1976. Mitochondrial calcium overload: a general mechanism for cell-necrosis in muscle diseases. Lancet. I: 672-674.

10. Schanne, F. A. X., A. B. Kane, E. E. Young, and J. L. Farber. 1979. Calcium dependence of toxic cell death: a final common pathway. Science (Wash. D. C.). 206: 700-702.

11. Bretherton, K. N., A. J. Day, and S. L. Skinner. 1977. Hypertension-accelerated atherogenesis in cholesterolfed rabbits. Atherosclerosis. 27: 79-87.

12. Holman, R. L., H. C. McGill, Jr., J. P. Strong, and J. C. Geer. 1958. Technics for studying atherosclerotic lesions. Lab. Invest. 7: 42-47.

13. Henry, P. D., R. Shuchleib, J. Favis, E. S. Weiss, and B. E. Sobel. 1977. Myocardial contracture and accumulation of mitochondrial calcium in ischemic rabbit heart. Am. J. Physiol. 233: H677-H684.

14. Lowry, O. H., N. J. Rosebrough, A. L. Farr, and R. J. Randall. 1951. Protein measurement with Folin phenol reagent. J. Biol. Chem. 193: 265-275.

15. Kates, M. 1972. Techniques of lipidology. In Laboratory Techniques in Biochemistry and Molecular Biology. T. and E. Work, editors. North-Holland Publishing Company, Amsterdam, Netherlands. 360.

16. Barr, A. J., J. H. Goodnight, J. P. Sall, W. H. Blair, and D. M. Chilko. 1979. Statistical Analysis System, SAS Institute, Inc., Raleigh, N. C. 237-263.

17. Jasmin, G., and B. Solymoss. 1975. Prevention of hereditary cardiomyopathy in the hamster by verapamil and other agents. Proc. Soc. Exp. Biol. Med. 149: 193-198.

18. Britt, B. A. 1979. Etiology and pathophysiology of malignant hyperthermia. Fed. Proc. 38: 44-48.

19. Publicover, S. J., C. J. Duncan, and J. L. Smith. 1978. The use of A 23187 to demonstrate the role of intracellular calcium in causing ultrastructural damage in mammalian muscle. J. Neuropathol. Exp. Neurol. 37: 544-557.

20. Thomas, W. A., H. Imai, R. A. Florentin, J. M. Reiner, and R. F. Skott. 1977. Smooth muscle and endothelial cell deaths iti atherogenesis studied by autoradiography. Prog. Biochem. Pharmacol. 14: 234-240.

21. Stary, H. C. 1977. Arterial cell injury and cell death in hypercholesterolemia and after reduction of high serum cholesterol levels. Prog. Biochem. Pharmacol. 14: 241-247.

22. Yokoyama, M., and P. D. Henry. 1979. Sensitization of isolated canine coronary arteries to calcium ions after exposure to cholesterol. Circ. Res. 45: 479-486.

23. Henry, P. D., J. L. Witztum, and M. Yokoyama. 1978. Vasoconstrictor effect of low density lipoprotein on canine coronary artery. Circulation. (Suppl. II) 58: 297 (Abstr.).

24. Heistad, D. D., M. L. Armstrong, and M. L. Marcus. 1981. Hyperemia of the aortic wall in atherosclerotic monkeys. Circ. Res. 48: 669-675.

25. Vater, W., G. Kroneberg, F. Hoffmeister, H. Kaller, K. Meng, A. Oberdorf, W. Puls, K. Schlossmann, and K. Stoepel. 1972. Zur Pharmakologie von 4-(2'-nitrophenyl)2,6 - dimethyl - 1,4 - dihydropyridin - 3,5 - dicarbonsauredi methylester (Nifedipine, BAY a 1040). Drug Res. 22: $1-14$.

26. Margolis, B., C. Lucas, and P. D. Henry. 1980. Effects of $\mathrm{Ca}^{++}$-antagonists on platelet aggregation and secretion. Circulation. (Suppl. III). 62: 191 (Abstr.).

27. Blackmore, P. F., M. El-Refai, and J. H. Exton. 1979. $\alpha$-Adrenergic blockade and inhibition of A 23187mediated $\mathrm{Ca}^{2+}$ uptake by the calcium antagonist verapamil in rat liver cells. Mol. Pharmacol. 15: 598-606. 